\title{
Heat responsive proteome changes reveal molecular mechanisms underlying heat tolerance in chickpea
}

\author{
Santisree Parankusam*, Pooja Bhatnagar-Mathur, Kiran K. Sharma \\ International Crops Research Institute for the Semi-Arid Tropics (ICRISAT), Patancheru, Hyderabad, 502324, Telangana, India
}

\section{A R T I C L E I N F O}

\section{Keywords:}

Chickpea

Cicer arietinum

Heat stress

Leaf proteomics

Gel-free proteomics

Heat tolerance

\begin{abstract}
A B S T R A C T
Understanding the molecular differences in plant genotypes contrasting for heat sensitivity can provide useful insights into the mechanisms that confer heat tolerance in plants. This study focuses on comparative physiological and proteomic analyses of heat-sensitive (ICC16374) and heat-tolerant (JG14) genotypes of chickpea (Cicer arietinum L.) under heat stress impositions at anthesis. Heat stress reduced leaf water content, chlorophyll content and membrane integrity with a greater impact on the sensitive genotype compared to the tolerant one that had higher total antioxidant capacity and osmolyte accumulation, and consequently less oxidative damage. This study identified a set of 482 heat-responsive proteins in the tolerant genotype using comparative gel-free proteomics. Besides heat shock proteins, proteins such as acetyl-CoA carboxylase, pyrroline-5-carboxylate synthase (P5CS), ribulose-1,5-bisphosphate carboxylase/oxygenase (RuBisCO), phenylalanine ammonia-lyase (PAL) 2, ATP synthase, glycosyltransferase, sucrose synthase and late embryogenesis abundant (LEA) proteins were strongly associated with heat tolerance in chickpea. Several crucial proteins were induced by heat exclusively in the heat-tolerant genotype. Comparative proteome profiling and pathway analysis revealed mitigating strategies including, accumulation of osmoprotectants, protected membrane transport, ribosome and secondary metabolite synthesis, activation of antioxidant and defense compounds, amino acid biosynthesis, and hormonal modulation that might play key roles in chickpea heat tolerance. This study potentially contributes to improved stress resilience by advancing our understanding on the mechanisms of heat tolerance in chickpea.
\end{abstract}

\section{Introduction}

Due to the ongoing climate change, rise in atmospheric temperature could be detrimental to plant growth. Heat stress causes inactivation of enzymes associated with various metabolic pathways, increases fluidity of membrane lipids, and results in protein denaturation and aggregation, that eventually lead to reduced growth and development. Nevertheless, plants respond to such stresses by reprogramming their proteins to ensure a steady state of vital metabolic processes that help them survive and function under stress conditions (Bokszczanin and Fragkostefanakis, 2013).

Chickpea (Cicer arietinum L.) is a cool-season, high-protein crop that complements cereal-based diets. Additionally, it is an important rotational crop due to its ability to symbiotically fix nitrogen. However, it is vulnerable to high temperatures $\left(\geq 35^{\circ} \mathrm{C}\right)$, especially at the reproductive stage (Young et al., 2004; Zinn et al., 2010; Devasirvatham et al., 2012a,b). Loss of pollen viability has been observed in many sensitive crops, including chickpea, as the main cause for reduced yield under heat stress (Sato et al., 2006; Devasirvatham et al., 2012a; Kaushal et al., 2013). This is mainly due to reduced accumulation of carbohydrates and altered source-sink dynamics in pollen grains and stigmatic tissues due to heat stress. Heat has a direct and detrimental effect on leaves, which are the major source of photoassimilates, and hence impacts the grain filling and biomass of the plant. For example, in tomato, the reduction of carbohydrates at critical stages of plant growth and development due to heat stress lead to reduced fruit set and yield (Sato et al., 2006). Similarly, in cowpea and chickpea, heat stress reduces soluble sugars in the anther walls and developing pollen grains that eventually result in decreased pollen viability (Ismail and Hall, 1999; Devasirvatham et al., 2012a; Kaushal et al., 2013). Indeed in the semi-arid regions, late-planted chickpea during the postrainy season matures in early summer when it is often exposed to receding moisture and heat stress. Moreover, The Intergovernmental Panel on Climate Change (IPCC) has forecast possible increment in the extreme annual daily maximum temperatures by about $2-5{ }^{\circ} \mathrm{C}$ by the late twenty-first century (http://www.ipcc.ch). Considering these predictions, screening

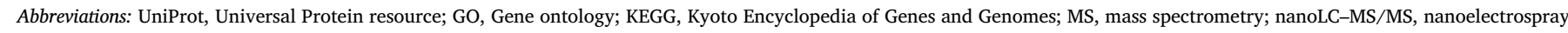
tandem mass spectrometry; qRT-PCR, quantitative real-time PCR; ROS, reactive oxygen species; SAMS, s-adenosylmethionine synthase; DEPs, differentially expressed proteins

* Corresponding author.

E-mail addresses: S.Parankusam@cgiar.org, santhikinnu@gmail.com (S. Parankusam). 
for heat-tolerant varieties and deciphering the mechanism of such tolerance is imperative for improving chickpea resilience to the impacts of climate change and for expanding its cultivation even under warmer climate and late-sown conditions.

While large genetic variations for thermo-tolerance have been observed in chickpea germplasm (Krishnamurthy et al., 2011), the basis of heat tolerance in contrasting genotypes has not been fully understood. Very few studies have addressed heat stress mitigating strategies in chickpea, mainly based on physiological and biochemical analysis under both in vivo and in vitro heat stress treatments (Kumar et al., 2012; Kaushal et al., 2013). While a few reports are based on molecular markers and transcriptomic studies taking lead from model plants like Arabidopsis thaliana and Medicago truncatula (Aranjuelo et al., 2011; Lan et al., 2011; Zhu and Provart, 2003; Kudapa et al., 2014), proteomic studies in legumes have been scanty (Ramalingam et al., 2015). Although the genomics and transcriptomics studies have generated large data sets, the corresponding proteomics data in genotypes contrasting to their heat stress responses will be very valuable to draw any conclusions from these studies (Ramalingam et al., 2015).

In recent years, proteomic approaches have been successfully used in unraveling responses to a wide range of abiotic stresses such as cold (Kosová et al., 2011; Rinalducci et al., 2011; Heidarvand and MaaliAmiri, 2013), drought (Benesova et al., 2012), heat (EchevarríaZomeño et al., 2015), flooding (Mustafa and Komatsu, 2014) and salt (Hu et al., 2013). Proteomic responses to heat stress have been investigated in the leaves of a number of food crops like rice, wheat, barley and maize where many stress-related proteins have been identified (Wang et al., 2015; Lee et al., 2007; Ng et al., 2014; Sule et al., 2004; Li et al., 2013). Up-regulation of heat shock proteins (Hsps) and antioxidant enzymes has been observed under heat stress in rice leaves (Lee et al., 2007). In Agrostis, heat response involved changes in proteins related to protection, energy and carbohydrate metabolism, redox homeostasis, protein synthesis and degradation (Zou et al., 2011). Similarly, Hsps and major proteins related to energy metabolism, redox homeostasis and signal transduction were shown to be significantly affected by high temperature in radish (Zhang et al., 2013). Despite similar advancements in soybean, applications of proteomics in analyzing heat stress tolerance in chickpea have not been reported yet (Ramalingam et al., 2015).

Gel-free proteomics is a highly sensitive and emerging technique that overcomes some of the limitations associated with gel-based techniques such as poor resolution and sensitivity, thereby improving the throughput and dynamic range of protein analyses. The present study attempts to understand the molecular basis of physiological responses to heat stress in contrasting chickpea genotypes by quantitative analyses of differentially expressed proteins (DEPs) that are responsible for heat stress tolerance. Under the current scenario of climate change, this study is important to enhance our understanding of the adaptation strategies in chickpea genotypes.

\section{Materials and methods}

\subsection{Plant material and growth conditions}

Chickpea (Cicer arietinum L.) seeds of stable heat-tolerant (ICCV92944 popularly known as JG 14) and heat-sensitive (ICC 16374) varieties were obtained from ICRISAT mini Core collection. These genotypes were earlier identified based on the field evaluation and yield performance under heat stress (Krishnamurthy et al., 2011). Ten plants each of two genotypes were grown in a glasshouse with one plant per pot. Initially, three seeds of each genotype were sown in 23-cm pots containing a mixture of vermicompost, sand and black vertisol soil (1:2:4), and eventually retaining only one plant per pot. The soil was prepared by sieving the vertisol through $1-\mathrm{cm}$ wire mesh and mixing uniformly with diammonium phosphate (DAP) and muriate of potash at the rate of $0.3 \mathrm{~g} \mathrm{~kg}^{-1}$ and $0.2 \mathrm{~g} \mathrm{~kg}^{-1}$ soil, respectively, and pasteurized twice. Pots were initially saturated with $2 \mathrm{~L}$ of water. Owing to differences in phenology of the two genotypes, these were sown on different dates to synchronize anthesis (35-41 days after sowing (DAS) for ICC 16374 and 39-44 DAS for ICCV92944). The seeds were treated with a fungicide (Thiram ${ }^{\circ}$ ) immediately before sowing, and the plants irrigated every three days. All chemicals used in this study were analytical grade.

\subsection{Heat stress impositions}

The selected chickpea genotypes were grown under green house conditions $\left(27 / 18^{\circ} \mathrm{C}\right.$ day/night temperatures) till flowering (42 and 46 DAS for ICC16374 and ICCV92944 respectively; i.e. 5 days after anthesis), following which five of the initially grown ten plants were shifted to growth chamber for heat stress treatment. The plants were exposed to gradual increasing temperatures @ two degrees per day (27/ $18{ }^{\circ} \mathrm{C}$ until $42 / 25^{\circ} \mathrm{C}$; day/night) for a period of 8 days thereafter referred to as heat stressed plants (Devasirvatham et al., 2012a), while the non-stressed control plants continued to grow in the glasshouse $\left(27 / 18^{\circ} \mathrm{C}\right)$. The temperature was maintained constantly in the growth room with a $15 \mathrm{~min}$ reciprocal transition period from day to night temperature. The growth room contained $72 \%$ input wattage of $1500 \mathrm{~mA}$ cool white fluorescent and $28 \%$ input wattage of Sylvania $50 \mathrm{~W}-277 \mathrm{~V}$ incandescent lighting. The light intensity (quantum) was about $320 \mu \mathrm{mol} \mathrm{s}^{-1} \mathrm{~m}^{-2}$ (Light meter model LI-189- Li-Cor, USA) during $12 \mathrm{~h}$ photoperiod $(08-20 \mathrm{~h})$ with $75-80 \%$ relative humidity. Careful watering ensured that moisture was not a limiting factor. To evaluate the effect of high temperature, fully opened young leaves from 2nd node from top were collected from individual plants after 8 days of incremental heat stress $\left(42 / 25^{\circ} \mathrm{C}\right)$ along with controls and flash frozen in liquid nitrogen before storing at $-80^{\circ} \mathrm{C}$ until further use. For biochemical and proteomic analyses, tissues from three individual plants per genotype per treatment (heat stressed and controls) were pooled, and the experiment was replicated thrice for statistical robustness.

\subsection{Relative water and chlorophyll contents}

The leaf relative water content (RWC), electrolyte leakage and chlorophyll content were measured at the end of the heat treatment imposed as described above. RWC (\%) was calculated as [(FW - DW)/ $(\mathrm{TW}-\mathrm{DW}){ }^{*} 100$, where FW $=$ Fresh weight, DW $=$ Dry weight, and TW $=$ Turgid weight (Barrs and Weatherley, 1962). Chlorophyll (Chl) content was determined by the method described by Arnon (1949). Fresh leaf samples $(0.5 \mathrm{~g})$ selected from contrasting genotypes were homogenized in a pre-cooled mortar and pestle with $10 \mathrm{~mL}$ of acetone $(80 \% \mathrm{v} / \mathrm{v})$ and the homogenate was centrifuged for $10 \mathrm{~min}$ at $5000 \mathrm{~g}$. Absorbance was measured with a UV-vis spectrophotometer at 663 and $645 \mathrm{~nm}$.

Stress injury to leaves was measured as electrolyte leakage (Premchandra et al., 1990). Thoroughly washed fresh leaf samples (1 g) were incubated at $25^{\circ} \mathrm{C}$ in $10 \mathrm{~mL}$ of deionized water on a rotary shaker for $24 \mathrm{~h}$ and the first electrical conductivity of the solution (L1) was determined. Leaf samples were then autoclaved at $120^{\circ} \mathrm{C}$ for $20 \mathrm{~min}$ and the final electrical conductivity (L2) was obtained. The electrolyte conductivity (EL) was calculated as per the equation: EL $(\%)=(\mathrm{L} 1 /$ L2)*100.

\subsection{Biochemical estimations}

\subsubsection{Hydrogen peroxide}

Hydrogen peroxide $\left(\mathrm{H}_{2} \mathrm{O}_{2}\right.$ ) was estimated following the method of Noreen and Ashraf (2009) where $0.1 \mathrm{~g}$ fresh leaf tissue was homogenized in $2 \mathrm{~mL}$ of $0.1 \%(\mathrm{w} / \mathrm{v})$ trichloroacetic acid (TCA) in a prechilled mortar, followed by centrifugation at $12,000 \times g$ for $15 \mathrm{~min}$ and the supernatant was collected. Absorbance of the reaction mixture consisting of $0.5 \mathrm{~mL}$ supernatant, $0.5 \mathrm{~mL}$ sodium phosphate buffer $(\mathrm{pH}$ 
7.0) and $1 \mathrm{~mL}$ of $1 \mathrm{M} \mathrm{KI}$ was read at $390 \mathrm{~nm} . \mathrm{H}_{2} \mathrm{O}_{2}$ content was determined by using an extinction coefficient of $0.28 \mu \mathrm{M} \mathrm{cm}^{-1}$ and expressed as $\mu \mathrm{mol} \mathrm{g}{ }^{-1} \mathrm{FW}$.

\subsubsection{Lipid peroxidation}

The levels of lipid peroxidation in the tissues of control and treated plants were quantified by the estimation of malondialdehyde (MDA) content, a breakdown product of lipid peroxidation. MDA was determined with thiobarbituric acid (TBA) reaction as described by Heath and Packer (1968). Leaf tissue $(0.3 \mathrm{~g})$ was extracted in $5 \mathrm{~mL}$ of $0.1 \%$ (w/v TCA). Following centrifugation, $1 \mathrm{~mL}$ aliquot of the supernatant was mixed with $20 \%(\mathrm{w} / \mathrm{v})$ TCA containing $0.5 \%(\mathrm{w} / \mathrm{v})$ TBA, heated at $95{ }^{\circ} \mathrm{C}$ for $30 \mathrm{~min}$ and cooled on ice. The mixture was subjected to centrifugation at $10,000 \mathrm{rpm}$ for $10 \mathrm{~min}$ followed by measuring the absorbance of the supernatant at $532 \mathrm{~nm}$. Correction for non-specific absorbance was done by subtracting the value at $600 \mathrm{~nm}$. Lipid peroxidation was expressed as $\mu \mathrm{mol} \mathrm{mL}^{-1}$ of MDA formed using an extinction coefficient of $155 \mathrm{mM} \mathrm{cm}^{-1}$.

\subsection{Estimation of free proline, soluble sugars and total antioxidant capacity}

The acid ninhydrin reaction was used to estimate the free proline content as described by Rahman et al. (2016). Soluble sugars were determined using Anthrone method (Dubois et al., 1956). The total antioxidant capacity assay kit from Oxiselect (Cat. No. STA-360) was used to determine the copper reducing equivalents in the tissue extract that are proportional to the total antioxidant power of the plant tissue. The protein concentration of each sample was determined following the Bradford (1976) method using BSA as a protein standard.

\subsection{Quantitative Real Time PCR ( $q R T-P C R$ )}

Leaves from each genotype were harvested at the end of heat stress imposition as mentioned above and frozen in liquid nitrogen. Total RNA was extracted from the pulverized frozen leaves using the RNeasy Plant Mini kit (Qiagen, Tokyo, Japan), and quantified with NanoDrop ND 1000 Spectrophotometer (USA) followed by DNase treatment using the Fermentas DNase Kit (Fermentas, Hanover, MD) as per the manufacturer's instructions. Two micrograms of DNase-treated RNA and $200 \mathrm{U}$ M-Mulv reverse transcriptase (Invitrogen) were used for first strand cDNA synthesis in a $20 \mu \mathrm{L}$ final volume. Relative Real-time PCR was performed in a total volume of $20 \mu \mathrm{L}$ using $5 \mathrm{ng}$ of cDNAs using the SYBR Green PCR Master Mix (Takara ${ }^{\circ}$ ) on a Realplex Real Time PCR system (Eppendorf ${ }^{\circ}$ ). Gene-specific primers for qPCR were designed using PRIMER3 software with the following parameters: $58-62{ }^{\circ} \mathrm{C}$ annealing temperature, $20-22$ bp primer length, $45-55 \%$ GC content, and 100-200 bp amplicon length (Supplementary Table 1). The analysis was performed as previously described (Santisree et al., 2011). The chickpea actin (CaActin) and elongation factor 4 (CaIF4) genes were used as control genes for normalization of cycle threshold (Ct) values. Relative fold expression was calculated by $2^{-\Delta \Delta \mathrm{Ct}}$ method (Anbazhagan et al., 2015).

\subsection{Protein analyses}

\subsubsection{Protein extraction}

Total protein was extracted from the leaf samples of contrasting genotypes grown under control and heat stress $\left(42^{\circ} \mathrm{C}\right)$ conditions. One $\mathrm{g}$ tissue was pulverized and homogenized in liquid nitrogen followed by suspension in $7 \mathrm{~mL}$ of extraction buffer containing $0.7 \mathrm{M}$ sucrose, $0.1 \mathrm{M}$ $\mathrm{KCl}, 100 \mathrm{mM}$ Tris buffer at pH 7.2, $50 \mathrm{mM}$ EDTA, $50 \mathrm{mM}$ dithiothreitol (DTT), $1 \mathrm{mM}$ phenylmethylsulfonyl fluoride (PMSF), and $25 \mu \mathrm{L}$ of protease inhibitor cocktail (Sigma-Aldrich, USA). Equal volume of trissaturated phenol was added and mixed thoroughly by shaking at $4{ }^{\circ} \mathrm{C}$ for $30 \mathrm{~min}$ followed by centrifugation at $20,000 \mathrm{~g}$ and $4^{\circ} \mathrm{C}$ for $30 \mathrm{~min}$. The upper phenolic phase was extracted twice as described above. The proteins were precipitated by adding $0.1 \mathrm{M}$ ammonium acetate containing $50 \mathrm{mM}$ DTT followed by centrifugation at $26,200 \mathrm{~g}$ for $30 \mathrm{~min}$ at $4{ }^{\circ} \mathrm{C}$. The protein pellet was washed twice with methanol and once with acetone containing $10 \mathrm{mM}$ DTT, and finally dissolved in $50 \mathrm{mM}$ ammonium bicarbonate. The amount of protein in each sample was quantified and normalized for equal concentrations by polyacrylamide gel electrophoresis. These protein samples were prepared for mass spectrometry by reduction and alkylation using $10 \mathrm{mM}$ DTT for $30 \mathrm{~min}$ and $25 \mathrm{mM}$ iodoacetamide for $45 \mathrm{~min}$, respectively, followed by overnight digestion with $2 \mu \mathrm{g}$ of sequencing grade porcine trypsin (Promega, USA) at $37{ }^{\circ} \mathrm{C}$ (Weinhold et al., 2015). To ensure reproducibility and accuracy of results, three biological replicates and three experimental replicates used in this study (three biological replicates * three experimental replicates * two treatments * two genotypes). Each sample was analyzed thrice (technical replicate) for minimizing run -to -run errors.

\subsubsection{LCMS analysis, fractionation, MS parameters and data analysis}

Following trypsin digestion, the peptide fragments were concentrated and reconstituted in $50 \mu \mathrm{L}$ of $0.1 \%$ formic acid. Approximately $600 \mathrm{ng}$ of each of the protein digests were loaded on to ACQUITY UPLC BEH C18 Column (Waters; Milford, MA, USA; Pore size-130 ̊, particle size- $1.7 \mu \mathrm{m}$, internal diameter- $2.1 \mathrm{~mm}$, length$50 \mathrm{~mm}, \mathrm{pH}$ range-1-12) with a 60 -min gradient run. Mobile phase A (95/5-water/acetonitrile with $0.1 \%(\mathrm{v} / \mathrm{v})$ formic acid) and mobile phase B (95/5-acetonitrile/water with $0.1 \%(\mathrm{v} / \mathrm{v})$ formic acid) were used to apply gradient for all the samples as follows: $2 \%-50 \%$ B (0-30 min), 50\% B hold (30-32 min), 50\%-80\% B (32-40 min), $80 \%-85 \%$ B ( $40-50 \mathrm{~min}$ ), $2 \%$ B hold ( $50-60 \mathrm{~min})$. The initial flow rate was $300 \mathrm{~nL} \mathrm{m^{-1 }}$ of $98 \%$ mobile phase A for $1 \mathrm{~min}$. The flow rate was maintained at $300 \mathrm{~nL} \mathrm{~min}^{-1}$ and the column temperature was kept at $40{ }^{\circ} \mathrm{C}$. The UPLC-separated peptides were analyzed for MS and MSMS fragmentation on SYNAPT G2 (Waters, Milford, MA, USA) with ESI source operated at a voltage of $3.5 \mathrm{kV}$, dissolution gas flow of $800 \mathrm{~L} / \mathrm{h}$ and a capillary temperature of $350{ }^{\circ} \mathrm{C}$. Mass spectra were obtained through data-dependent acquisition in positive and resolution mode using the following settings (Da Range: $130-1500$ Da; Scan Time: 0.5 s; Collision Energy: 1. Low Energy: Trap: $6 \mathrm{~V}$, Transfer: $6 \mathrm{~V}$; 2. High Energy: Trap Collision Energy Ramp: 20-45 V; Transfer Collision Energy Ramp: OFF; Cone Voltage: 40 V) (Weinhold et al., 2015). Following data acquisition, the continuum LC-MS data were processed and searched using ProteinLynx GlobalServer version 2.3 (PLGS 2.3; Waters). Raw data sets were processed incorporating ion detection, deisotoping, deconvolution, and peak lists ( ${ }^{*}$.pkl files) produced based on the allocation of precursor ions and fragments with similar retention times. Components with mass precision of $10 \mathrm{ppm}$ and time tolerance of $0.25 \mathrm{~min}$ are typically clustered together. Elevated energy ions with low energy precursor peptide ions with an approximate precision of $0.05 \mathrm{~min}$ were aligned. A downloaded UniProt chickpea database (http://www.uniprot.org/) was used to search each triplicate run with the following parameters: Trypsin was chosen as the primary digest reagent, carbamidomethyl (Cys) as a fixed modification and oxidation (Met) as a variable modification, a maximum of one missed cleavage event and peptide tolerances of $\pm 50 \mathrm{ppm}$ and $100 \mathrm{ppm}$ for the fragment tolerance. Minimum number of fragment matches for proteins is 5 , minimum number of fragment matches for peptides is 2 and minimum number of peptide matches for protein is 2 . Ion scores of greater than 44 were considered significant $(p<0.05)$. The proteins were identified only if they matched at least one unique top-ranking peptide with an expected value $\leq 0.05$. The highest-scoring protein was selected from the list in cases where a peptide was matched to multiple proteins. The protein identifications were based on the detection of at least three fragment ions per peptide with more than two peptides identified per protein with a false discovery rate of $5 \%$ (Shen et al., 2009).

The quantitative analysis of protein abundance was carried out 
using Waters ExpressionE, which is part of PLGS 2.3 based on measuring peptide ion peak intensities noted in low collision energy mode in a triplicate set. PLGS "autonormalization" function was used for data normalization where the data were normalized based on inbuilt statistical analysis taking into account of the intensity of the many consistent qualitatively matched proteins (or peptides). All the processed protein hits were thus identified with a confidence of $95 \%$. The peptides which are identical from each triplicate set per genotype/treated sample were clustered on the basis of mass precision of $5 \mathrm{ppm}$ and a retention time tolerance of $0.25 \mathrm{~min}$ using an in-built clustering software of PLGS 2.3. Proteins which passed the criteria of minimum two peptides, represented in biological replicates, 1.5-fold up- or downregulation and a $p$-value of less than 0.05 were considered as significantly different between genotypes/treatments. The mass spectrometry proteomics data have been deposited to the ProteomeXchange Consortium (Vizcaíno et al., 2014) via the PRIDE partner repository with the dataset identifier PXD005578.

\subsection{Functional annotation and pathway mapping}

The identified proteins were classified into Gene Ontology (GO) categories from the UniProt (www.uniprot.org) database. The proteins were mapped and identified to the reference canonical pathways of chickpea in the Kyoto Encyclopedia of Genes and Genomes (KEGG) database (http://www.genome.jp/tools). The protein-protein interaction network was built based on the high score corresponding homologous proteins from Arabidopsis database using STRING (http://string$\mathrm{db}$. org/) with high confidence interaction score of 0.700 (Szklarczyk et al., 2015).

\subsection{Statistical analysis}

The data was analyzed using Sigmaplot (ver.11) based on the mean and standard error (SE) values in all assays including dose response and biochemical studies. Statistically significant differences between treatments were determined by one-way ANOVA using the StudentNewman-Keuls method.

\section{Results}

\subsection{Effect of heat stress on reactive oxygen species, lipid peroxidation and free proline}

A significant variation was observed in heat-stress injury between the two tested chickpea genotypes. The heat stress injury in contrasting genotypes was assessed in comparison with their respective controls by various biochemical measurements such as chlorophyll content, MDA content, electrolyte leakage, reactive oxygen species (ROS) etc. The leaf chlorophyll content was reduced by heat stress in both the genotypes than control plants while genotype ICC 16374 exhibited lower total leaf chlorophyll than JG14 under heat stress (Fig. 1a). Likewise, the leaf water status also significantly decreased due to heat stress in the heatsensitive genotype, although not much difference was observed under control conditions (Fig. 1b). Heat stress stimulated the accumulation of MDA and electrolyte leakage compared to controls in both the genotypes as an indicative of heat-induced lipid peroxidation and membrane damage (Fig. 1c, d). The electrolyte leakage was $20-25 \%$ greater in the sensitive genotype when compared to the tolerant genotype under heat stress. Similarly, MDA content also increased (10-15\%) in the leaves of ICC 16374, relative to little damage in the heat-tolerant genotype JG14 (Fig. 1d). The heat induced increase in the level of $\mathrm{H}_{2} \mathrm{O}_{2}$ was also at least two times higher in the sensitive genotype compared to the tolerant genotype (Fig. 2a), corresponding to three times in comparison to unstressed controls. Genotype JG14 showed higher total antioxidant capacity (TAC) than the sensitive genotype (Fig. 2b), suggesting an enhanced capacity to control heat-induced oxidative damage. Increased accumulation of osmolytes in the tolerant genotype was noted where proline showed a fivefold increased accumulation with enhanced heat stress in the tolerant genotype, whereas the sensitive genotype accumulated relatively lower proline (three fold) when compared to their unstressed plants (Fig. 2c). Similarly, under heat stress, soluble sugars accumulated notably in tolerant genotype than the sensitive one (Fig. 2d).

\subsection{Identification of differentially expressed proteins (DEPs) by quantitative proteomic analysis}

After removing the redundant and invalid identifiers from individual samples, over 1013 proteins in the sensitive and 624 proteins in the tolerant genotype were identified under normal growth (control) conditions, while 1013 and 699 proteins matched to unique ids across the UniProt database under heat stress in the sensitive and tolerant genotypes, respectively. To understand the heat tolerance mechanism in tolerant genotype JG14, it is important to understand the differentially expressed proteins in tolerant genotype in comparison with the sensitive one. Hence, the identified proteins were compared based on their up- and down-regulation due to the given heat stress treatment. Only significant proteins represented consistently in the biological replicates and showing at least 1.5 fold change in expression were only used for analysis. Based on the expression, the identified proteins were categorized into two groups: 1) heat responsive proteins common in both genotypes but differentially regulated and 2) genotype specific proteins specifically present in or absent from tolerant genotype under heat stress (Fig. 3a).

\subsection{Functional cataloging of heat responsive DEPs in both genotypes}

Proteins in this category were heat responsive in both the genotypes, following differential expression patterns. Out of 154 such heatresponsive proteins, 94 showed an increase while 60 decreased in abundance in the tolerant genotype (JG14) when compared to the sensitive genotype (Fig. 3a; Supplementary data Sheet 1 ). These significantly $(\mathrm{P}<0.05 ; 1.5$ fold $)$ up- and down-regulated proteins were compared based on the number of proteins involved in biological process (Fig. 3b). For a better understanding of the proteomic responses under heat stress, these DEPs were further grouped into various functional categories. A detailed ontological classification of total DEPs resulted in categorization of 132 proteins based on molecular function, 49 proteins based on cellular location and 100 proteins based on biological processes (Fig. 3c). As expected, some of the differentially accumulated proteins were identified in multiple groups. The analysis suggested involvement of a majority of these DEPs in various metabolic processes (35\%) and cellular processes (25\%) followed by proteins involved in response to stimulus (18\%) while the rest involved in single organism process, biogenesis, and developmental process (Supplementary data Sheet 1; Fig. 3c). The prediction of subcellular localization of these DEPs revealed that most of the DEPs were localized to the cell $(24 \%)$, organelle $(20 \%)$, cell membrane $(18 \%)$ and macromolecular complexes (9\%) (Fig. 3c). STRING analysis indicated considerable interaction networks among the seven photosynthesis related proteins including NDH-2-platoquinone reductase, photosystem b components, ribulose-bisphosphate carboxylase large subunit, ATP synthase subunit A and 11 ribosomal family proteins including 40S Ribosomal Protein (RP)S3A, S19E, RPS2, RPS7, RPL16A with at least 1.5-fold increase in the tolerant genotype under heat stress (Fig. 3d). Such interactions of differentially expressed proteins were also identified among heat shock proteins and aminoacid synthesis related proteins. Our data indicated that photosynthesis and protein biosynthesis remained intact in the leaves of tolerant genotype even after exposure to heat stress. The STRING analysis also suggested that proteins involved in proline and methionine biosynthesis and heat shock proteins were also showed strong interactions under heat stress. The proteins altered more than 

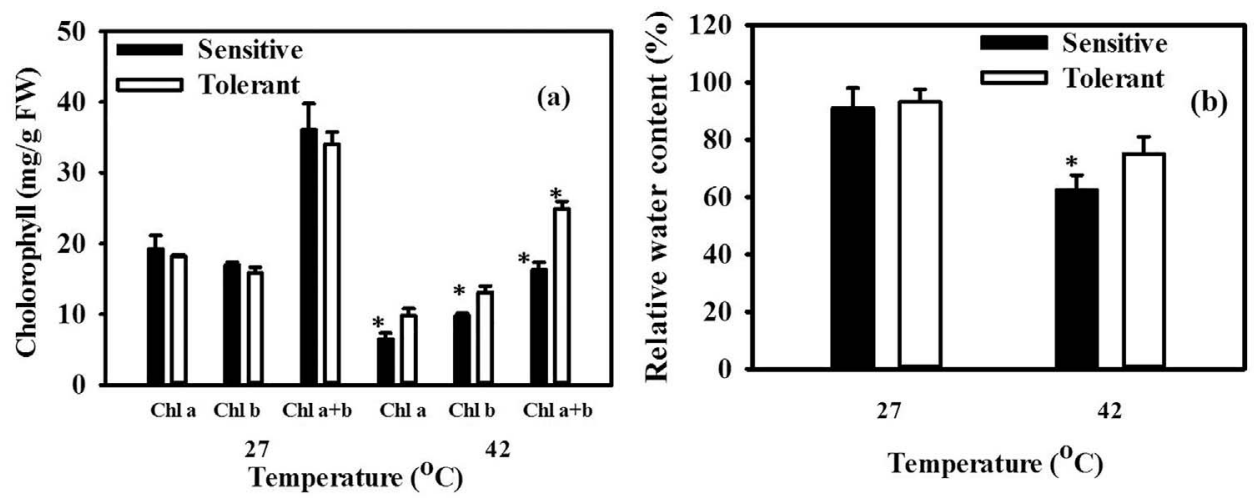

Fig. 1. Effect of heat stress on physiological characteristics of contrasting chickpea genotypes. (a) Effect of heat stress $\left(42{ }^{\circ} \mathrm{C}\right)$ on leaf chlorophyll content, (b) leaf relative water content and (c) relative electrolyte leakage, and (d) lipid peroxidation, measured as leaf melonaldehyde (MDA) content in contrasting chickpea genotypes. The leaf tissues were collected from a minimum of 3 independent plants and the experiment was repeated three times. Data are means \pm SE of three replications. Asterisk (*) indicates a statistically significant difference in response to the heat treatment ( $\mathrm{p}<0.05$ ).
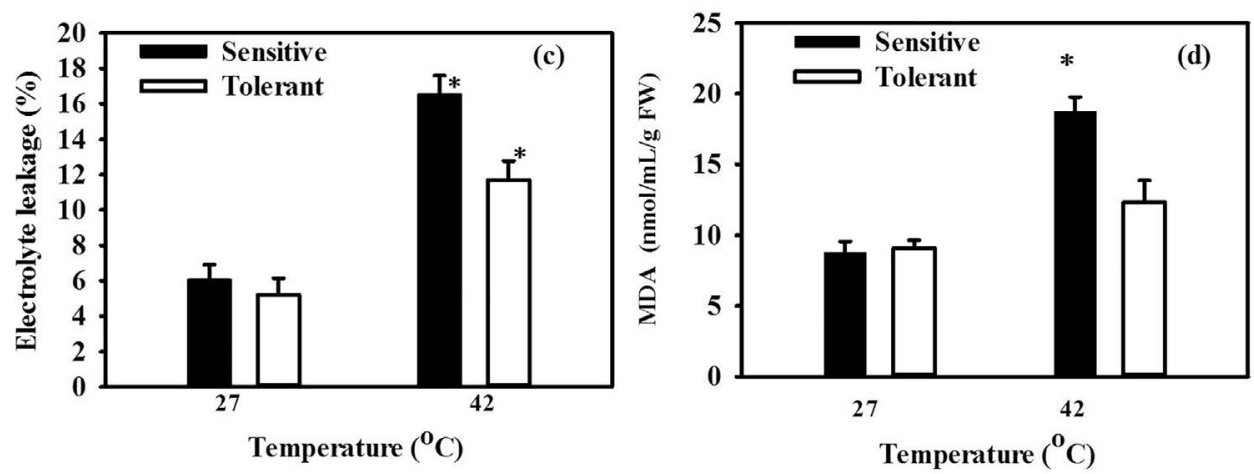

fivefold were considered as the most significant DEPs and listed in Table 1. Nevertheless, few heat responsive proteins from both the genotypes could not be identified by the UniProt chickpea database and hence were matched with their corresponding homologous proteins using Uniprot blast. The proteins with significant identities with the corresponding homologs from other plant species were listed in Table 2.

\subsection{Proteins specific to- and absent from-tolerant genotype under heat} stress

This group represents the genotype specific proteins that significantly changed in their abundance by heat stress in at least one of the genotypes. A total of 230 proteins present in the sensitive genotype were undetected or absent from tolerant genotype while 98 unique proteins were specifically expressed only in tolerant genotype under
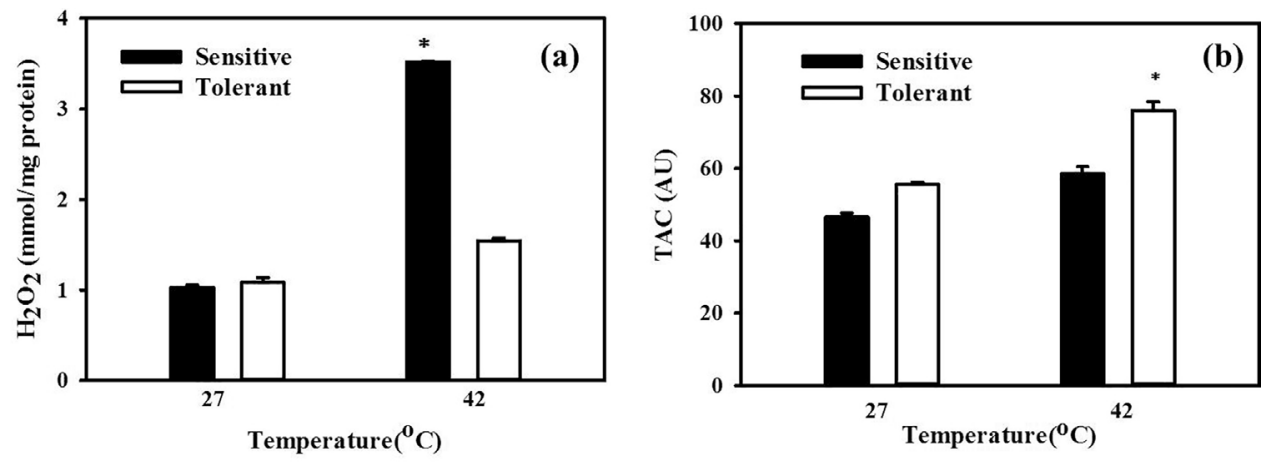

Fig. 2. Effect of heat stress on (a) leaf $\mathrm{H}_{2} \mathrm{O}_{2}$, (b) total antioxidant capacity (TAC), represented in arbitory units, (c) proline and (d) soluble sugar content in thermally contrasting chickpea genotypes. Leaves were collected from heat sensitive genotype ICC 16374 and tolerant genotype JG14 grown under control $\left(27^{\circ} \mathrm{C}\right)$ and heat stressed $\left(42{ }^{\circ} \mathrm{C}\right)$ condition as described in methods. The values are the means \pm SE $(n=3)$ of three independent experiments. The asterisk (*) shows significant differences among genotypes under heat stress at $\mathrm{p}<0.05$.
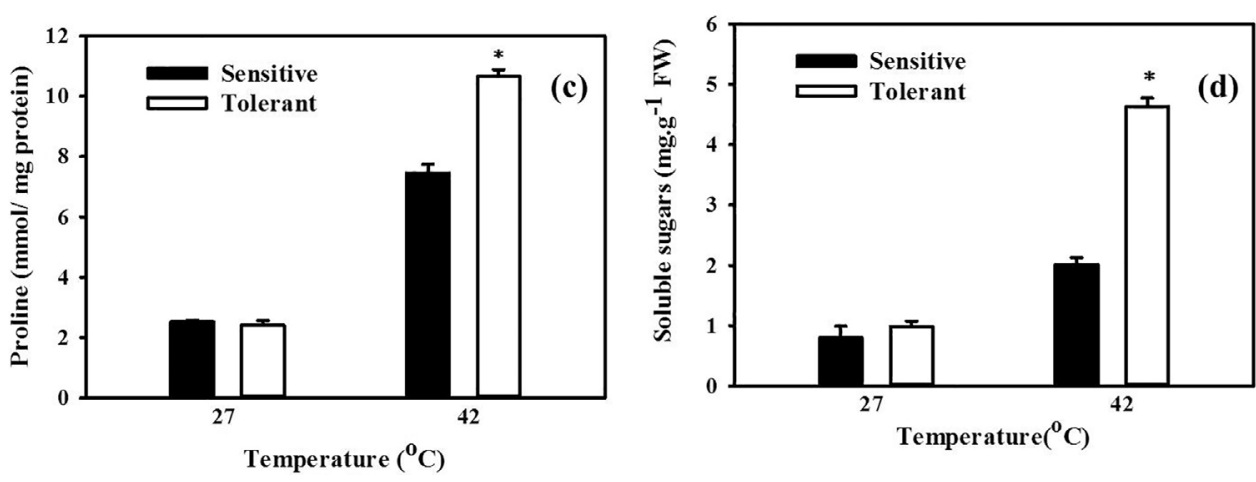
(a)
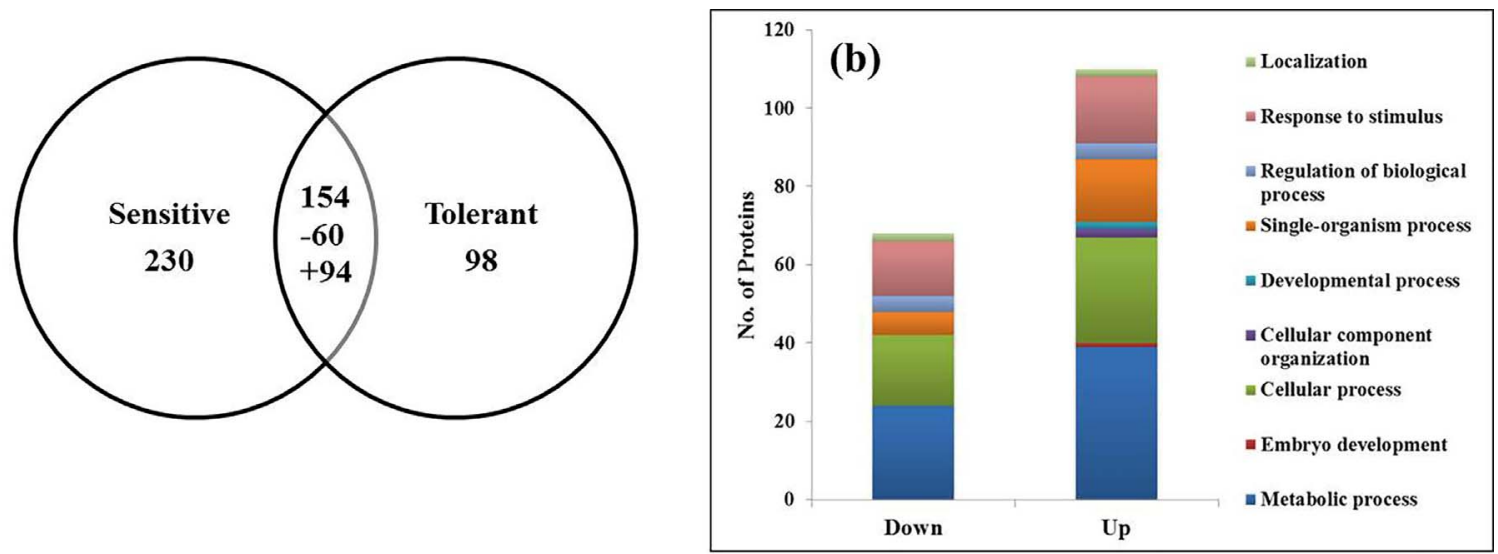

(c)
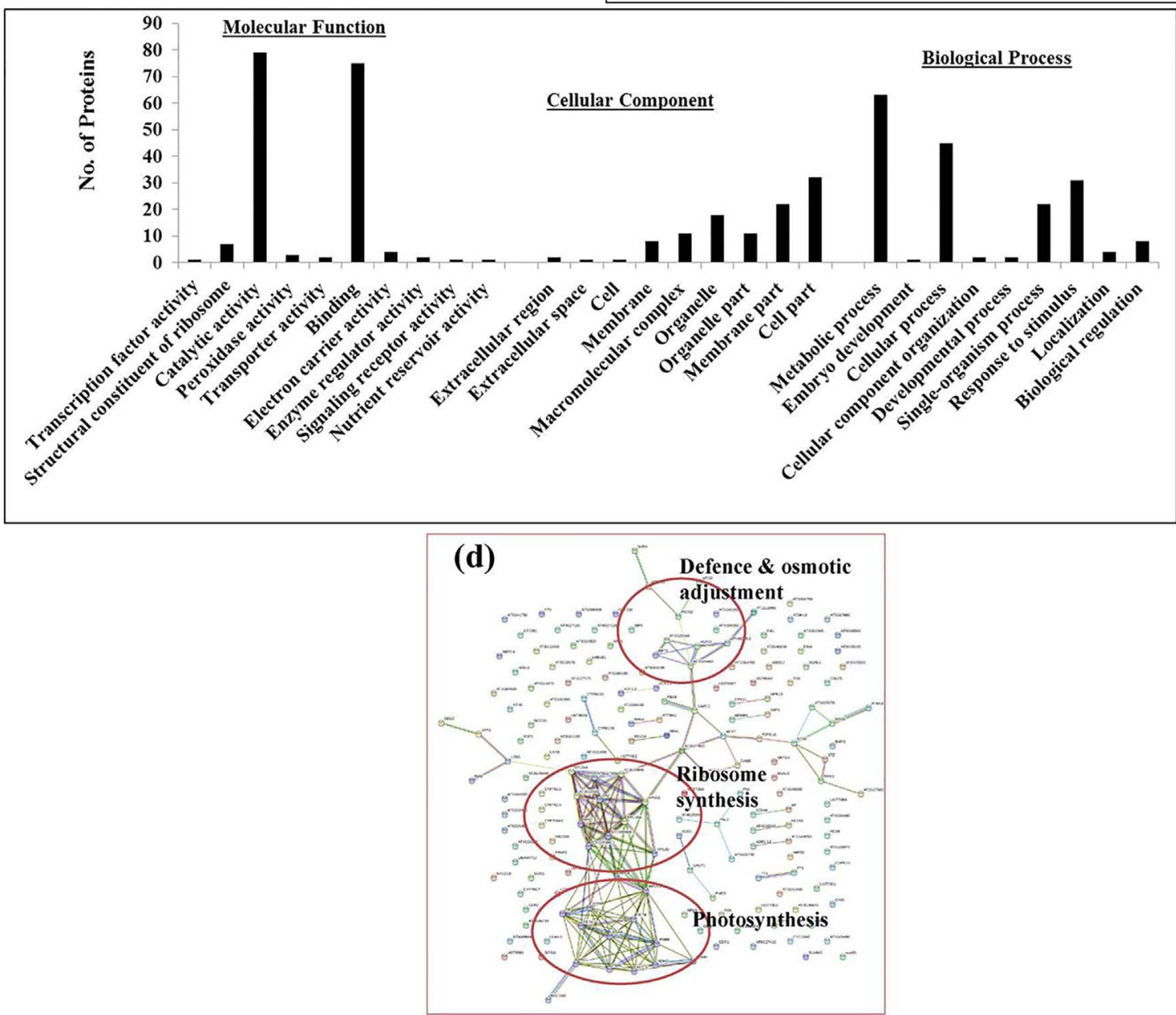

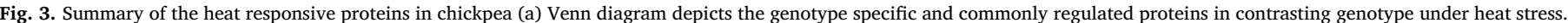

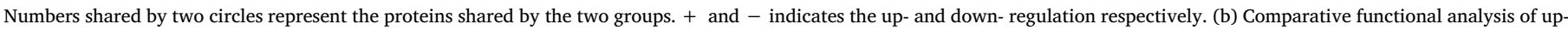

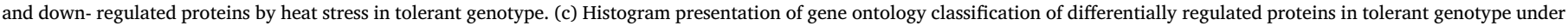

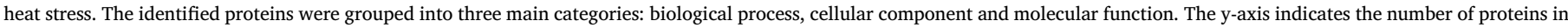

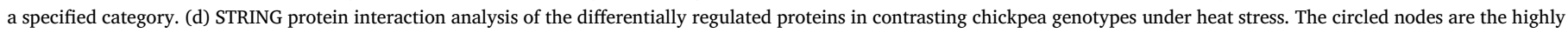
active networks under heat stress.

heat stress (Fig. 3a; Supplementary data Sheet 2). Some of the heattolerant genotype-specific proteins include cystathionine gamma-synthase, abscisate beta-glucosyltransferase, 1-aminocyclopropane-1-carboxylate oxidase, photosystem II protein D2 and glutathione peroxidase. Some of the crucial proteins silenced by heat stress in tolerant genotype include mitochondrial ATP synthase subunit epsilon, photosystem II protein D1, nodulin-35, peroxidase 42-like, non-cyanogenic beta-glucosidase, malate dehydrogenase. The functional classification of these unique and silenced proteins in the tolerant genotype JG14 was indicated in Fig. 4a $\&$ b respectively.

To identify the proteins involved in various metabolic pathways, the total heat responsive proteins $(154+230+98)$ in the tolerant genotype were subjected to pathway analysis. A total of 202 proteins were mapped to 207 KEGG IDs, while 43 proteins were associated with various metabolic pathways (Supplementary Fig. 1). The heat responsive proteins in tolerant genotype were found to be mainly involved in processes such as synthesis of secondary metabolites (22), ribosome synthesis (20), photosynthesis (12) oxidative phosphorylation 


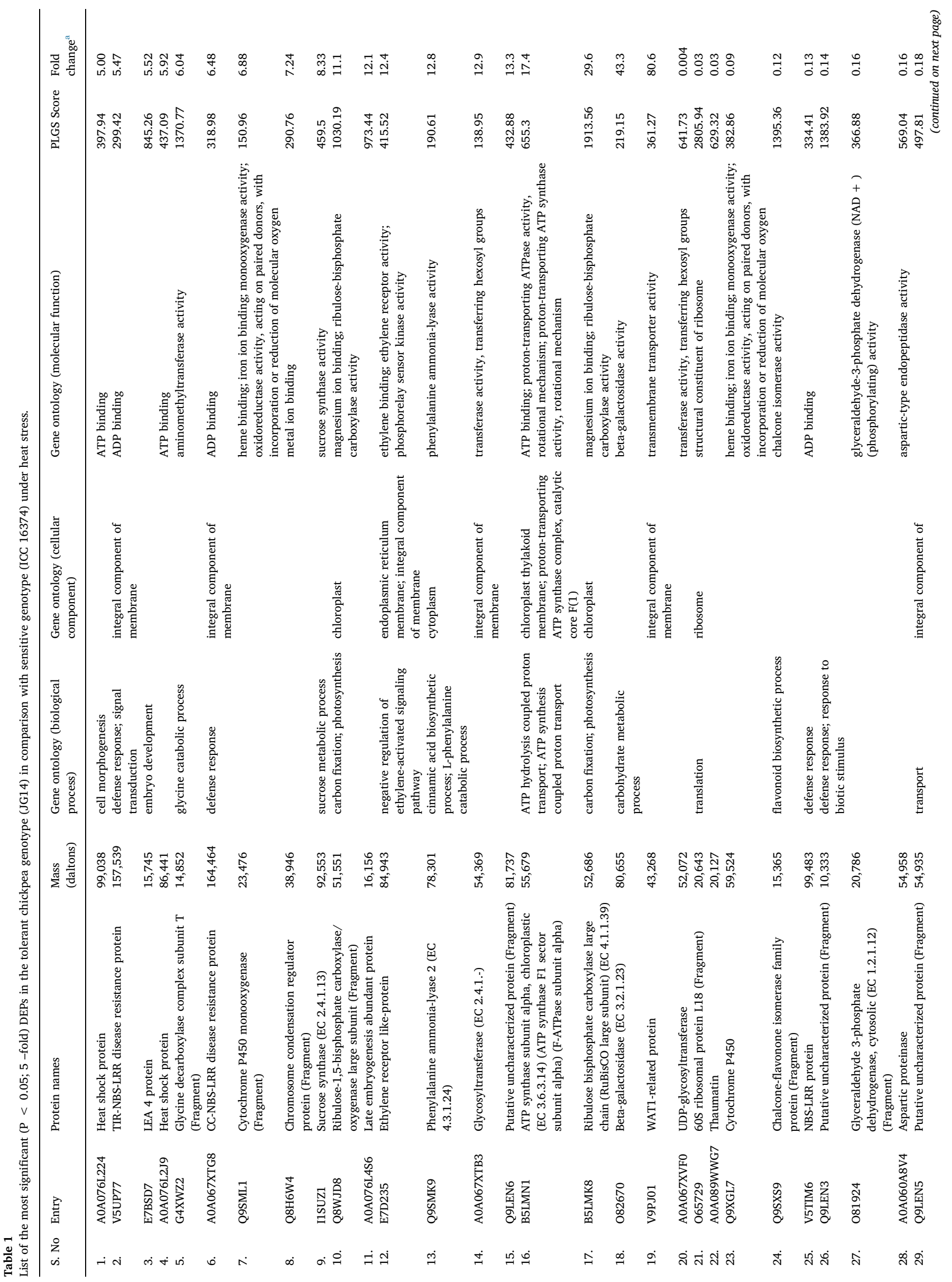


(7), amino acid biosynthesis (5), starch and sucrose metabolism (3). In addition, proteins encoding enzymes such as acidic endochitinase-like (EC:3.2.1.14), P5CS; delta-1-pyrroline-5-carboxylate synthase-like, PAL2; phenylalanine ammonia-lyase 2-like (EC:4.3.1.24), sr5a; verylong-chain enoyl-CoA reductase-like, proteasome subunit beta type-5like (EC:3.4.25.1), monodehydroascorbate reductase (EC:1.6.5.4), threonine synthase 1, chloroplastic (EC:4.2.3.1), SAMS; S-adenosylmethionine synthase-like (EC:2.5.1.6) were identified to be mainly involved in inducing heat stress tolerance in JG14.

\subsection{Proteins related to photosynthesis and energy metabolism}

Several crucial proteins related to photosynthesis and energy metabolism were found to be up-regulated under heat stress in the genotype JG14 (Supplementary data Sheet 1). These included ribulose-1,5bisphosphate carboxylase/oxygenase large subunit, photosystem I P700, chlorophyll a apoprotein A2 and fructose-bisphosphate aldolase (Supplementary data Sheet 1). Apart from photosynthesis, proteins involved in the carbon metabolism and tricarboxylic acid (TCA) cycle such as cytochrome b6, cytochrome f and ATP synthase alpha and beta subunits were also up-regulated in the tolerant genotype, possibly to provide more energy under heat.

\subsection{Signal transduction and heat shock proteins}

This study could identify some proteins with proven role in heat tolerance. Proteins such as heat shock proteins, GDP dissociation inhibitor, ethylene receptor-like and NBS-LRR proteins were observed to be up-regulated in the tolerant genotype under heat stress, thereby suggesting an increased heat stress-induced intracellular transport and signal transduction (Supplementary data Sheet 1). In addition, a number of protein kinases such as MAP kinases, which can profoundly influence survival, were activated in the tolerant genotype by heat stress (Supplementary Fig. 2) These MAP kinases can modulate various defense responses such as maintenance of ROS levels, ethylene synthesis etc.

\subsection{Proteins involved in nucleic acid metabolism and translation}

Heat stress is known to induce significant changes in nucleic acid metabolism and accumulation of ribosomal proteins (Supplementary data Sheet $1 \& 2$ ). Nascent polypeptide-associated complex (NAC) family transcription factor 4 involved in transcription was up-regulated in tolerant genotype upon heat stress. In fact, heat stress enhanced the accumulation of specific ribosomal proteins in the tolerant genotype, suggesting composition of the ribosomes as an important event for adaptation of stress challenges. Ribosomal protein S2, S4, S7, L33, L24 and GTP-binding nuclear protein involved in ribosome biogenesis in eukaryotes were also up-regulated in the heat-tolerant genotype.

\subsection{Metabolism related proteins}

This study uncovered several heat-induced proteins involved in a variety of metabolic pathways in the heat-tolerant genotype JG14 (Supplementary Fig. 1). Some of those important enzymes included cystathionine gamma-synthase, 1-aminocyclopropane-1-carboxylate oxidase, abscisate beta-glucosyltransferase were exclusively appeared in the tolerant genotype under heat stress. Acetyl-CoA carboxylase beta subunit that may be involved in the regulation of membrane lipids; inositol-3-phosphate synthase-like, and ribulose-1,5-bisphosphate carboxylase/oxygenase involved in photosynthesis; UDP-glucuronic acid decarboxylase 6-like, sucrose synthase related to sugar metabolism; flavoprotein WrbA and phenylalanine ammonia-lyase 2-like protein involved in biosynthesis of secondary metabolites were also heat responsive in the tolerant genotype. While legumin was up-regulated, the nodulation signaling pathway 2 protein was down-regulated by heat 
Table 2

Closest homologue of unknown heat-responsive DEPs search by BLASTP (http://www.uniprot.org/blast/).

\begin{tabular}{|c|c|c|c|c|c|}
\hline Accession & Gene id & Homologue Name & Species & Identity (\%) & E-value \\
\hline C5YH85 & 8060900 & Putative uncharacterized protein Sb07g025360 & Sorghum bicolor & 100 & 1.9E-106 \\
\hline A0A151RA37 & & Trafficking protein particle complex subunit 2-like protein & Cajanus cajan & 99 & $1.8 \mathrm{E}-70$ \\
\hline B7FN82 & 11416940 & Mps one binder kinase activator-like protein $1 \mathrm{~A}$ & Medicago truncatula & 99 & 7.4E-137 \\
\hline A0A151TAA0 & 11417595 & Amino acid kinase family protein & Medicago truncatula & 96 & $1.2 \mathrm{E}-148$ \\
\hline G7L1T5 & 11431330 & O-linked GlcNAc transferase-like protein & Medicago truncatula & 96 & $3.4 \mathrm{E}-67$ \\
\hline A0A072U6I0 & 25495273 & SPFH/band 7/PHB domain membrane-associated family protein & Medicago truncatula & 95 & 0 \\
\hline A0A072VCU5 & 25487969 & SNAP receptor complex protein & Medicago truncatula & 94 & 4.3E-118 \\
\hline A0A072UG57 & 25495117 & Coiled-coil vesicle tethering-like protein, putative & Medicago truncatula & 93 & 6.7E-68 \\
\hline A0A072UZJ4 & 25489487 & Purple acid phosphatase & Medicago truncatula & 91 & $2.2 \mathrm{E}-145$ \\
\hline A0A072UT48 & 25488601 & Disease resistance protein (TIR-NBS-LRR class), putative & Medicago truncatula & 88 & $2.4 \mathrm{E}-91$ \\
\hline G7LCN6 & 11446200. & Calcium-dependent lipid-binding (CaLB domain) family protein & Medicago truncatula & 85 & $230 \mathrm{E}-87$ \\
\hline G7IMZ2 & 11420052 & Disease-resistance response protein & Medicago truncatula & 83 & $4 \mathrm{E}-47$ \\
\hline A0A151U4W0 & & Transcription factor bHLH96 & Cajanus cajan & 82 & 2.3E-89 \\
\hline I1NGP3 & 11411651 & Molybdenum cofactor sulfurase & Medicago truncatula & 82 & $3.8 \mathrm{E}-96$ \\
\hline A0A072UHJ3 & 25491230 & Pyridoxamine 5'-phosphate oxidase family protein & Medicago truncatula & 81 & 0 \\
\hline G7LDJ8 & 11439883 & Cytochrome P450 family protein & Medicago truncatula & 81 & 7.5E-63 \\
\hline Q2PF01 & & Putative cytosolic factor & Trifolium pratense & 81 & 0 \\
\hline G7LBG6 & 11406035 & Trehalose-6-phosphate synthase domain protein & Medicago truncatula & 81 & $7 \mathrm{E}-80$ \\
\hline A0A072TGZ0 & 25480207 & BAG family molecular chaperone regulator-like protein & Medicago truncatula & 81 & 2.1E-139 \\
\hline
\end{tabular}

(a)

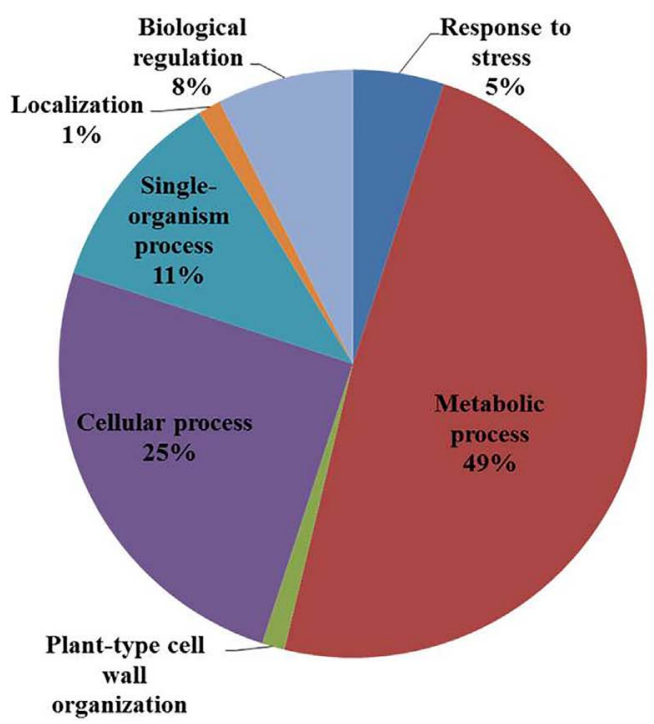

(b)

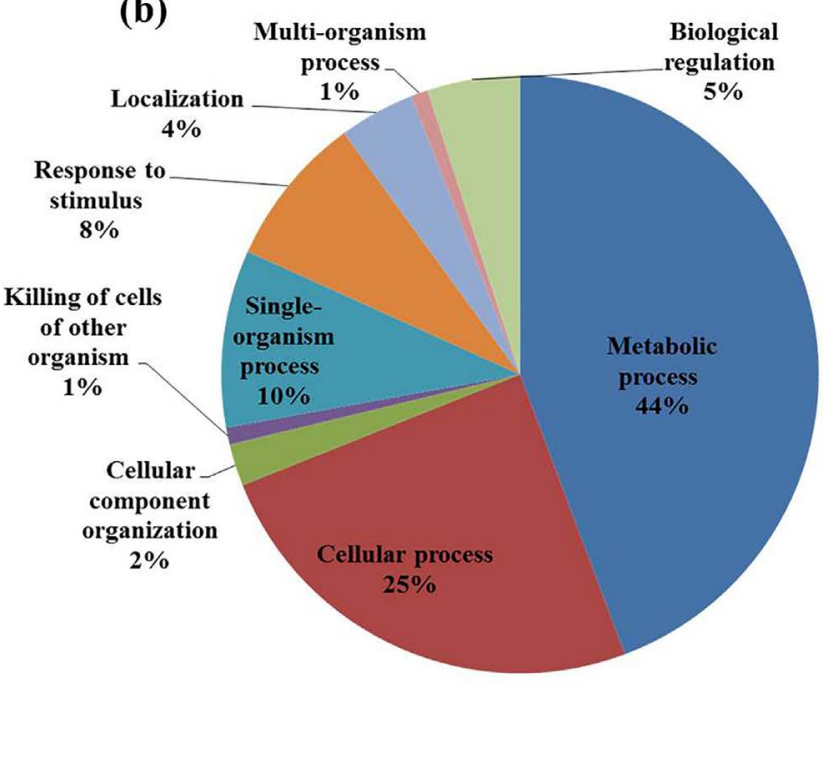

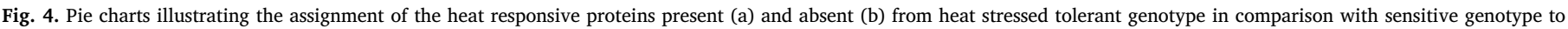
functional groups according to biological processes. The classification was according to Uniprot ontology.

stress in the tolerant genotype.

\subsection{Cell wall components and membrane transporters}

An important element in heat stress tolerance is membrane lipid saturation. The up-regulation of beta glactosidase, pectinesterase 3-like and UDP-glucuronic acid decarboxylase 6-like suggested enhanced cell wall reorganization events in JG14 compared to the sensitive genotype (Supplementary data Sheet 1). The proteins such as WAT-1, GDP dissociation inhibitor, ATP synthase subunits were increased in abundance in JG14 suggesting enhanced transport activities across membranes under heat stress.

\subsection{Enhanced amino acid metabolism related proteins}

Amino acids are precursors for a large array of proteins and metabolites vital during extensive metabolic shifts under heat stress condition. The key enzymes in amino acid synthesis such as methyltetrahydropteroyltriglutamate-homocysteine methyltransferase catalyzing the synthesis of methionine and cysteine; delta-1-pyrroline-5-carboxylate synthase (P5CS) involved in proline and arginine synthesis; phenylalanine ammonia-lyase involved in aromatic amino acid synthesis were enhanced in JG14 under heat stress, in contrast to S-adenosylmethionine synthase (SAMS) that decreased in abundance (Supplementary data sheet 1 ).

\subsection{Proteins involved in response to stimulus and signaling}

Plant hormones such as abscisic acid and ethylene are known to play a vital role in plant adaption to adverse environmental conditions. However, hormonal content, compartmentalization and homeostasis may vary depending on the stress condition and this reflects in the plant's response to stress. Several essential proteins such as TIR-NBSLRR-disease resistance protein, 1-amino-cyclopropane-1-carboxylic acid oxidase, ethylene receptor protein, putative ABA-responsive protein and peroxidases were induced by heat in tolerant genotype JG14, thereby strongly supporting its ability to survive during prevailing heat stress condition (Supplementary data Sheet 1). 


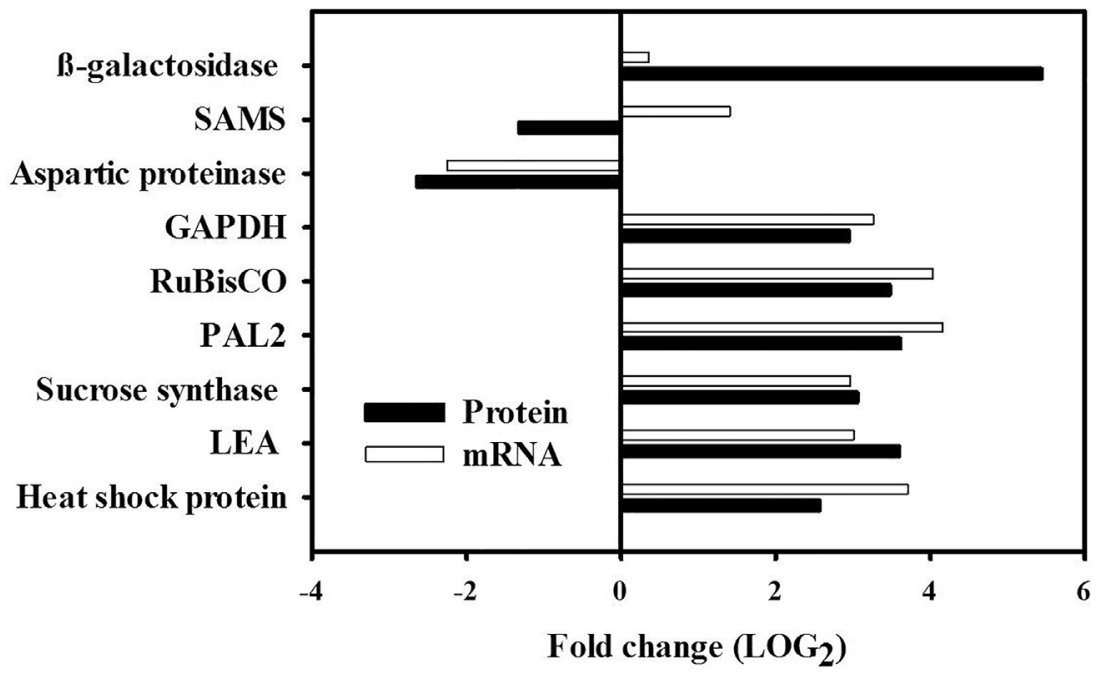

Fig. 5. The correlation of mRNA and protein expression levels of few selected most significant DEPs using quantitative real time-PCR. The logarithmic base 2 transformed fold change values of tolerant vs sensitive under heat stress $\left(42{ }^{\circ} \mathrm{C}\right)$ of protein and mRNA are plotted as graph. SMAS: S-adenosyl methionine synthase, GAPDH: glyceraldehyde 3-phosphate dehydrogenase, RuBisCO: ribulose-1,5-bisphosphate carboxylase/oxygenase, PAL; phenylalanine ammonia-lyase, LEA: late embryogenesis abundant protein.

\subsection{Correlation between protein and mRNA levels of selected proteins}

To ascertain whether the changes in protein abundance are related to changes at the transcriptome level, mRNA expression of some of the significant candidate DEPs were analyzed using real time-PCR (Fig. 5). In both the tested genotypes, the mRNA expression of, sucrose synthase, heat shock protein, LEA, PAL2, and aspartic proteinase changed significantly in the leaves upon heat stress treatment. While enhanced expression of heat shock protein, RuBisCO, PAL2, sucrose synthase, glyceraldehyde 3-phosphate dehydrogenase (GAPDH) and LEA genes were observed in JG14, the expression of aspartic proteinase was down regulated at both transcript and protein levels. However, the heat induced mRNA expression of SAMS in JG14 did not correlate with the reduced protein abundance in response to heat stress (Fig. 5).

\section{Discussion}

The mechanisms to tolerate heat involve changes in morphological, physiological and molecular events that often vary among genotypes (Huang and Gao, 1999). Thus, understanding these key differences among genotypes can provide valuable insights for devising strategies for improving crop performance. Most of the studies on heat stress in chickpea have mainly focused on physiological or transcriptomic approaches (Wang et al., 2006; Kumar et al., 2012; Kudapa et al., 2014). However, since protein metabolic processes, including synthesis and degradation, are most sensitive to rising temperatures, proteomics research on heat stress could greatly contribute to the understanding of its consequences. Hence, the present study characterized proteins to illuminate the genotype-specific modulation of leaf proteome in response to heat stress in contrasting chickpea genotypes. In this study a set of 482 heat responsive proteins were identified in the tolerant genotype (Fig. 3a; Supplementary data sheet $1 \& 2$ ). While, some of these heat responsive proteins were common to both genotypes and significantly altered in their expression. Several metabolic proteins such as monodehydroascorbate reductase, pectinesterase 3 , phenylalanine ammonialyase 2-like, cystathionine gamma-synthase, adenosylmethionine synthase, NADH dehydrogenase subunit, Cytochrome b6, inositol-3-phosphate synthase, RNA polymerase, ATP synthase subunit alpha, NBS-LRR protein etc. appeared to be strongly related to heat response in chickpea. Additionally, a number of genotype-specific and heat stressresponsive proteins identified in our study may offer possible candidates for augmenting tolerance against heat stress. Nevertheless, these could be classified into three categories based on their expression. 1) Proteins enhanced in abundance in tolerant genotype but reduced in sensitive genotype, such as PAL 2, beta galactosidase, glucanase, sucrose synthase, WAT1 like transporter etc., 2) Proteins that are induced in heat sensitive genotype but repressed in the tolerant one for example, SAMS, monodehydroascorbate reductase etc. 3) Lastly, several proteins under heat stress were specific to one genotype and not expressed in the other. For example, cystathionine gamma-synthase, 1-aminocyclopropane-1-carboxylic acid oxidase, abscisate beta-glucosyltransferase, flavoprotein etc. expressed in the tolerant genotype, whereas others such as adenosylhomocysteinase, malate dehydrogenase expressed only in the heat-sensitive genotype. The quantitative and comparative proteome profiling of contrasting chickpea genotypes revealed approximately 154 heat-induced DEPs from category $1 \& 2$ that are involved in a number of biological processes, including proteins coding for cell wall-modifying enzymes, heat shock proteins and amino acid biosynthesis.

High temperatures negatively affect various physiological processes including photosynthesis, primary and secondary metabolism, lipids, and hormone signaling (Bita and Gerats, 2013). Photosynthetic processes being directly related to plant productivity are often more sensitive to heat stress and hence considered as priority for crop improvement studies. Several studies have demonstrated decrease in the abundance of photosynthesis and carbon metabolism related proteins as a main consequence of heat stress in plants (Li et al., 2013; Rocco et al., 2013). RuBisCO catalyzes the most crucial step of carbon fixation. In our study, we found up-regulated RuBisCO proteins in the tolerant genotype, possibly due to the enhanced photosynthesis in the tolerant genotype when compared to the sensitive genotype under heat stress. Further, some other photosynthesis related proteins were also found to be abundant in tolerant genotype, included fructose-bisphosphate aldolase, a key enzyme involved in maintaining the $\mathrm{CO}_{2}$ assimilation rate through RuBP regeneration, which is in line with previous reports ( $\mathrm{Li}$ et al., 2013). Similarly, increased abundance of photosystem (PS) I P700 and chlorophyll a apoprotein A2 were indicative of stable photosystem I in the tolerant genotype under heat stress. However, it will be difficult to rule out the possible impact of differential light intensities under natural sunlight vis a vis the artificial light source in growth chambers on the accumulation of chlorophyll and expression of these light responsive proteins. This calls for further validation of function of these DEPs to elucidate their role in the thermo-tolerance of chickpea.

Heat-induced reduction in carbon fixation and the consequent oxygen evolution result in the generation of harmful ROS. The production of ROS leads to membrane damage accompanied by ion leakage that is detrimental to chlorophyll and the photosynthetic apparatus, thereby resulting in diminished plant productivity (Camejo et al., 2006). In our study, a significant reduction in the $\mathrm{H}_{2} \mathrm{O}_{2}$ content and increased total antioxidant capacity was noticed in the tolerant genotype, which was also reflected in better water and chlorophyll content in leaves, suggesting that protection against injuries due to oxidative 
stress is a major heat stress survival mechanism in chickpea. In contrast, a substantial impact of high temperature on the sensitive genotype of chickpea was evident by enhanced electrolyte leakage, and high MDA and $\mathrm{H}_{2} \mathrm{O}_{2}$ content upon stress imposition when compared to the tolerant genotype, associating this response to increased lipid peroxidation, and protein degradation (Savchenko et al., 2000). The diverse expression patterns of a number of peroxidase isoforms are suggested to be involved in various physiological and stress responses (Choi and Hwang, 2012). While the different peroxidases exhibited differential expression to heat stress in the tolerant chickpea genotype, monodehydroascorbate reductase was down-regulated. The reduced monodehydroascorbate reductase and peroxidases are an indicative of the lower oxidative stress in the tolerant genotype. The up-regulated peroxidase might be involved in ROS scavenging, and in cell wall strengthening. Increased membrane fluidity due to heat stress lead to disruption of membrane transport, $\mathrm{Ca}^{2+}$ influx and cytoskeletal reorganization affecting the signal transduction and transport (Hasanuzzaman et al., 2013). Based on our results, we speculate that the tolerant genotype appeared to have relatively higher membrane integrity as evident by lower MDA levels, reduced electrolyte leakage and abundance of membrane reorganization proteins such as acetylCoA carboxylase, pectin esterase etc. thereby reduced heat stress injury to membranes.

In agreement with the previous reports, our results suggest that the accumulation of osmoprotectants could be another strategy adopted by the tolerant genotype to cope with heat stress in chickpea (BhatnagarMathur et al., 2009). A remarkable increase in proline content in the tolerant genotype correlated well with enhanced expression of P5CS. While heat stress hastened the decline in chlorophyll content with a consequent reduction in photosynthesis and carbohydrate availability in the sensitive chickpea genotype, a greater reducing sugar content, which can increase carbon availability and osmoprotection during various events of stress adaption, was observed in the tolerant genotype (Kaushal et al., 2013). Similarly, a greater expression of sucrose synthase at mRNA and protein levels was observed in tolerant chickpea genotype, which is in agreement with previous studies where the accumulated thermo-protectant metabolites were shown to be due to the up-regulation of sucrose synthase in thermo-tolerant Agrostis grass species (Xu and Huang, 2008). Heat stress induced repression of sucrose synthase and other invertases in the developing pollen grains often account for reduced soluble sugars in many crop plants such as chickpea, tomato and wheat (Yan et al., 2008). In support of this notion, we also observed an increased abundance of sucrose synthase and subsequent accumulation of soluble sugars in the tolerant genotype reasserting its probable role during heat stress tolerance. This may ensure successful fertilization events due to the sustained pollen viability even under heat stress that translates into the enhanced pod set and yield reported earlier in tolerant genotype (Krishnamurthy et al., 2011). In addition to this, prolonged heat stress even after fertilization often results in erroneous embryo development leading to reduced seed vigor and germination ultimately affecting seedling establishment (Bita and Gerats, 2013). However, in the present study, the abundance of LEA proteins and heat shock proteins in the tolerant genotype of chickpea substantiate the protecting mechanisms to the prevailing heat and drought conditions.

Another well-known aspect of heat-induced damage is the disruption of nucleic acids and macromolecules resulting in altered transcription. In fact, an enhanced accumulation of specific ribosomal proteins was observed in tolerant chickpea genotype suggesting that the protection of synthesis and synthesis of different sets of proteins is an important event for adaptation to stress challenges. An increased abundance of few enzymes catalyzing the synthesis of aminoacids such as 5-methyltetrahydropteroyltriglutamate-homocysteine methyltransferase, cystathionine gamma-synthase, threonine synthase, P5CS suggests the resumption of protein synthesis that contribute to the biomass and nutritional quality of the crop. Some of these amino acids in the heat tolerant genotype also serve as precursors for a number of signaling molecules such as nitric oxide, hydrogen sulphide, ethylene and polyamines. However, a decreased abundance of SAMS indicated inhibition of lignification or polyamine accumulation by heat stress even in the tolerant genotype as was observed previously in rice (Xu and Huang, 2008). Nonetheless, the mRNA expression of SAMS in tolerant genotype did not correlate with the observed protein levels in response to heat stress (Fig. 5). This low correlation might be due to the difference in the half-life of mRNA and protein, post translational regulation, differential gene expression of different copies of the same gene, or could be a significant noise in quantitative measurement of mRNA and proteins. Many previous studies on heat stress in plants have assigned a central role to the heat shock proteins (HSPs) for augmenting stress tolerance (Wang et al., 2014) that serve as molecular chaperones in protecting vital proteins. Similarly, the protective functions of LEA proteins have been proposed in various stress tolerance responses (Gao and Lan, 2016). These have distinct mechanism from regular molecular chaperones in protection of proteins and cellular structures from stress damage. Moreover, a repression of proteases such as cysteine protease was also observed in the tolerant genotype indicating reduced protein degradation under heat stress.

Key proteins in the phenylpropanoid pathway such as PAL2, chalcone synthase, anthocyanidin 3-O-glucosyltransferase were also induced by heat stress to a greater extent in the tolerant genotype. Heat induced activation of PAL and subsequent accumulation of phenolics were also reported previously in tomato as part of its acclimation to heat stress (Rivero et al., 2001). PAL is responsible for biosynthesis of several secondary metabolites like lignins, anthocyanins and flavanols that are generally involved in stress defence and hormone biosynthesis. In addition, several crucial proteins exhibited genotype specific expression contributing to differential response to heat stress (Supplementary data sheet 2).

Our study underscored the role of proteins involved in various vital pathways such as photosynthesis, electron transport, and amino acid metabolism serving as important molecular components in heat stress tolerance. The data suggested that heat tolerance mechanisms in chickpea is potentially characterized by an increased carbon assimilation, induction of heat shock proteins in conjunction with higher levels of antioxidants and osmolytes. These possibly maintained integrity of membranes, protected macromolecules and sustained metabolism, leading to heat acclimatization. Correlation of protein expression with transcript levels also suggested a coordinated and mechanistic approach towards heat stress tolerance in chickpea. Nevertheless, for biotechnological applications further characterization on regulation and post-translational modifications of these candidate proteins, their specific roles in heat stress tolerance need to be undertaken. Our efforts on molecular dissection of these mechanisms has not just advanced our understanding of heat tolerance associated factors/proteins, but would also be imperative for increasing the pace of crop improvement efforts and successful deployment of robust technologies. Notwithstanding, addressing multigenic traits like heat tolerance requires holistic approaches that integrate classical phenotyping and breeding strategies with the modern technologies there by effectively linking the "protein to phenotype" in order to achieve comprehensive understanding at a systems level. Moreover pyramiding genes for key component traits would be critical to achieve the required on-ground tolerance in the context of the ensuing climate change.

\section{Conflicts of interest statement}

The authors declare that the research was conducted in the absence of any commercial or financial relationships that could be construed as a potential conflict of interest. 


\section{Author contributions}

PS, PBM and KKS conceived and designed the study. PS conducted the experimental work and wrote the draft manuscript. PBM helped in analysis of the results and manuscript writing, KKS revised the manuscript. All authors discussed the results and reviewed the manuscript.

\section{Acknowledgments}

This work was supported by a financial grant to PS through the INSPIRE Faculty Award (IFA12-LSPA-08) from the Department of Science and Technology, Government of India, and partial funding from the CGIAR Research Program on Grain Legumes. We than Dr. Pooran M. Gaur for providing the seeds of chickpea genotypes used in this study.

\section{Appendix A. Supplementary data}

Supplementary data associated with this article can be found, in the online version, at http://dx.doi.org/10.1016/j.envexpbot.2017.07.007.

\section{References}

Anbazhagan, K., Bhatnagar-Mathur, P., Vadez, V., Dumbala, S.R., Kavi Kishor, P.B., Sharma, K.K., 2015. DREB1A overexpression in transgenic chickpea alters key traits influencing plant water budget across water regimes. Plant Cell Rep. 34, 199-210. http://dx.doi.org/10.1007/s00299-014-1699-z.

Aranjuelo, I., Molero, G., Erice, G., Avice, J.C., Nogues, S., 2011. Plant physiology and proteomics reveals the leaf response to drought in alfalfa (Medicago sativa L.). J. Exp. Bot. 62, 111-123. http://dx.doi.org/10.1093/jxb/erq249.

Arnon, D.I., 1949. Copper enzyme in isolated chloroplasts: polyphenoloxidase in Beta vulgaris. Plant Physiol. 24, 1-15.

Barrs, H.D., Weatherley, P.E., 1962. A re-examination of the relative turgidity technique for estimating water deficits in leaves. Aust. J. Biol. Sci. 24, 519-570. http://dx.doi. org/10.1071/BI9620413.

Benesova, M., Hola, D., Fischer, L., Jedelsky, P.L., Hnilicka, F., Wilhelmova, N., et al., 2012. The physiology and proteomics of drought tolerance in maize: early stomatal closure as a cause of lower tolerance to short-term dehydration? PLoS One 7, e38017. http://dx.doi.org/10.1371/journal.pone.0038017.

Bhatnagar-Mathur, P., Vadez, V., Devi, M.J., Lavanya, M., Vani, G., Sharma, K.K., 2009. Genetic engineering of chickpea (Cicer arietinum L.) with the P5CSF129A gene for osmoregulation with implications on drought tolerance. Mol. Breed. 23, 591-606. http://dx.doi.org/10.1007/s11032-009-9258-y.

Bita, C.E., Gerats, T., 2013. Plant tolerance to high temperature in a changing environment: scientific fundamentals and production of heat stress-tolerant crops. Front. Plant Sci. 4, 273. http://dx.doi.org/10.3389/fpls.2013.00273.

Bokszczanin, K.L., Fragkostefanakis, S., 2013. Perspectives on deciphering mechanisms underlying plant heat stress response and thermotolerance. Front. Plant Sci. 4, 315 http://dx.doi.org/10.3389/fpls.2013.00315.

Bradford, M., 1976. A rapid and sensitive method for the quantitation of microgram quantities of protein utilizing the principle of protein-dye binding. Ann. Biochem. 72, 248-254. http://dx.doi.org/10.1016/0003-2697(76)90527-3.

Camejo, D., Jiménez, A., Alarcón, J.J., Torres, W., Gómez, J.M., Sevilla, F., 2006. Changes in photosynthetic parameters and antioxidant activities following heat-shock treatment in tomato plants. Funct. Plant Biol. 33, 177-187. http://dx.doi.org/10.1071/ FP05067.

Choi, H.W., Hwang, B.K., 2012. The pepper extracellular peroxidase CaPO2 is required for salt, drought and oxidative stress tolerance as well as resistance to fungal pathogens. Planta 235, 1369-1382. http://dx.doi.org/10.1007/s00425-011-1580-z.

Devasirvatham, V., Gaur, P.M., Mallikarjuna, N., Tokachichu, R.N., Trethowan, R.M Tan, D.K.Y., 2012a. Effect of high temperature on the reproductive development of chickpea genotypes under controlled environments. Funct. Plant Biol. 39, 1009-1018. http://dx.doi.org/10.1071/FP12033.

Devasirvatham, V., Tan, D.K.Y., Gaur, P.M., Raju, T.N., Trethowan, R.M., 2012b. High temperature tolerance in chickpea and its implications for plant improvement. Crop Pasture Sci. 63, 419-428. http://dx.doi.org/10.1071/CP11218.

Dubois, M., Gilles, K., Hamilton, J.K., Robers, P.A., Smith, A.F., 1956. Colorimetric method for the determination of sugar and related substances. Ann. Chem. 28 350-356. http://dx.doi.org/10.1021/ac60111a017.

Echevarría-Zomeño, S., Fernández-Calvino, L., Castro-Sanz, A.B., López, J.A., Vázquez, J., Castellano, M.M., 2015. Dissecting the proteome dynamics of the early heat stress response leading to plant survival or death in Arabidopsis. Plant Cell Environ. 39, 1264-1278. http://dx.doi.org/10.1111/pce.12664.

Gao, J., Lan, T., 2016. Functional characterization of the late embryogenesis abundant (LEA) protein gene family from Pinus tabuliformis (Pinaceae) in Escherichia coli. Sci. Rep. 6, 19467. http://dx.doi.org/10.1038/srep19467.

Hasanuzzaman, M., Nahar, K., Alam, M.M., Roychowdhury, R., Fujita, M., 2013. Physiological, biochemical, and molecular mechanisms of heat stress tolerance in plants. Int. J. Mol. Sci. 14, 9643-9684. http://dx.doi.org/10.3390/ijms14059643.

Heath, R.L., Packer, L., 1968. Photoperoxidation in isolated chloroplasts. I. Kinetics and stoichiometry of fatty acid peroxidation. Arch. Biochem. Biophys. 125, 189-198. http://dx.doi.org/10.1016/0003-9861(68)90654-1.

Heidarvand, L., Maali-Amiri, R., 2013. Physio-biochemical and proteome analysis of chickpea in early phases of cold stress. J. Plant Physiol. 170, 459-469. http://dx.doi. org/10.1016/j.jplph.2012.

Hu, Y., Guo, S., Li, X., Ren, X., 2013. Comparative analysis of salt-responsive phosphoproteins in maize leaves using $\mathrm{Ti}^{4+}$-IMAC enrichment and ESI-Q-TOF MS. Electrophoresis 34, 485-492. http://dx.doi.org/10.1002/elps.201200381.

Huang, B., Gao, H., 1999. Physiological responses of diverse tall fescue cultivars to drought stress. HortScience 34, 897-901.

Ismail, A.M., Hall, A.E., 1999. Reproductive-stage heat tolerance, leaf membrane thermostability and plant morphology in cowpea. Crop Sci. 39, 1762-1768. http://dx. doi.org/10.2135/cropsci1999.3961762x.

Kaushal, N., Awasthi, R., Gupta, K., Gaur, P.M., Siddique, K.H.M., Nayyar, H., 2013. Heatstress-induced reproductive failures in chickpea (Cicer arietinum) are associated with impaired sucrose metabolism in leaves and anthers. Funct. Plant Biol. 40, 1334-1349. http://dx.doi.org/10.1071/FP13082.

Kosová, K., Vitamvas, P., Prasil, I.T., Renaut, J., 2011. Plant proteome changes under abiotic stress - contribution of proteomics studies to understanding plant stress response. J. Proteom. 74, 1301-1322. http://dx.doi.org/10.1016/j.jprot.2011.02.006.

Krishnamurthy, L., Gaur, P.M., Basu, P.S., Chaturvedi, S.K., Tripathi, S., Vadez, V., Rathore, A., Varshney, R.K., Gowda, C.L.L., 2011. Large genetic variation for heat tolerance in the reference collection of chickpea (Cicer arietinum L.) germplasm. Plant Genet. Res. 9, 59-69. http://dx.doi.org/10.1017/S1479262110000407.

Kudapa, H., Azam, S., Sharpe, A.G., Taran, B., Li, R., Deonovic, B., Cameron, C., Farmer, A.D., Cannon, S.B., Varshney, R.K., 2014. Comprehensive transcriptome assembly of chickpea (Cicer arietinum L.) using Sanger and Next Generation Sequencing platforms: development and applications. PLoS One 9, 1-12. http://dx.doi.org/10.1371/ journal.pone.0086039.

Kumar, S., Kaushal, N., Nayyar, H., Gaur, P.M., 2012. Abscisic acid induces heat tolerance in chickpea (Cicer arietinum L) seedlings by facilitated accumulation of osmoprotectants. Acta Physiol. Plant. 34, 1651-1658. http://dx.doi.org/10.1007/s11738-012 0959-1.

Lan, P., Li, W., Wen, T.N., Shiau, J.Y., Wu, Y.C., et al., 2011. iTRAQ protein profile analysis of Arabidopsis roots reveals new aspects critical for iron homeostasis. Plant Physiol. 155, 821-834. http://dx.doi.org/10.1104/pp.110.169508.

Lee, D.G., Ahsan, N., Lee, S.H., Kang, K.Y., Bahk, J.D., et al., 2007. A proteomic approach in analyzing heat-responsive proteins in rice leaves. Proteomics 7, 3369-3383. http://dx.doi.org/10.1002/pmic.200700266.

Li, W., Wei, Z., Qiao, Z., Wu, Z., Cheng, L., et al., 2013. Proteomics analysis of alfalfa response to heat stress. PLoS One 8, e82725. http://dx.doi.org/10.1371/journal. pone.0082725.

Mustafa, G., Komatsu, S., 2014. Quantitative proteomics reveals the effect of protein glycosylation in soybean root under flooding stress. Front. Plant Sci. 5, 627. http:// dx.doi.org/10.3389/fpls.2014.00627.

Ng, Z.X., Chua, K.H., Kuppusamy, U.R., 2014. Proteomic analysis of heat treated bitter gourd (Momordica charantia L. var. Hong Kong Green) using 2D-DIGE. Food Chem. 148, 155-161. http://dx.doi.org/10.1016/j.foodchem.2013.10.025.

Noreen, Z., Ashraf, M., 2009. Change in antioxidant enzymes and some key metabolites in some genetically diverse cultivars of radish (Raphanus sativus L.). Environ. Exp. Bot. 67, 395-402. http://dx.doi.org/10.1016/j.envexpbot.2009.05.011.

Premchandra, G.S., Sameoka, H., Ogata, S., 1990. Cell membrane stability, an indication of drought tolerance, as affected by applied nitrogen in soil. J. Agric. Res. 115, 63-66. http://dx.doi.org/10.1017/S0021859600073925.

Rahman, A., Mostofa, M.G., Nahar, K., Hasanuzzaman, M., Fujita, M., 2016. Exogenous calcium alleviates cadmium-induced oxidative stress in rice (Oryza sativa L.) seedlings by regulating the antioxidant defense and glyoxalase systems. Braz. J. Bot. 39, 393-407. http://dx.doi.org/10.1007/s40415-015-0240-0.

Ramalingam, A., Kudapa, H., Pazhamala, L.T., Weckwerth, W., Varshney, R.K., 2015. Proteomics and metabolomics: two emerging areas for legume improvement. Front. Plant Sci. 6, 1116. http://dx.doi.org/10.3389/fpls.2015.01116.

Rinalducci, S., Egidi, M.G., Karimzadeh, G., Jazii, F.R., Zolla, L., 2011. Proteomic analysis of a spring wheat cultivar in response to prolonged cold stress. Electrophoresis 32, 1807-1818. http://dx.doi.org/10.1002/elps.201000663.

Rivero, R.M., Ruiz, J.M., Garcia, P.C., López-Lefebre, L.R., Sánchez, E., Romero, L., 2001. Resistance to cold and heat stress: accumulation of phenolic compounds in tomato and watermelon plants. Plant Sci. 160, 315-321. http://dx.doi.org/10.1016/S01689452(00)00395-2.

Rocco, M., Arena, S., Renzone, G., Scippa, G.S., Lomaglio, T., Verrillo, F., et al., 2013. Proteomic analysis of temperature stress-responsive proteins in Arabidopsis thaliana rosette leaves. Mol. Biosyst. 9, 1257-1267. http://dx.doi.org/10.1039/c3mb70137a.

Santisree, P., Nongmaithem, S., Vasuki, V., Sreelakshmi, Y., Ivanchenko, M.G., Sharma, R., 2011. Tomato root penetration in soil requires a co-action between ethylene and auxin signaling. Plant Physiol. 156, 1424-1438. http://dx.doi.org/10.1104/pp.111. 177014.

Sato, S., Kamiyama, M., Iwata, T., Makita, N., Furukawa, H., Ikeda, H., 2006. Moderate increase of mean daily temperature adversely affects fruit set of Lycopersicon esculentum by disrupting specific physiological processes in male reproductive development. Ann. Bot. 97, 731-738. http://dx.doi.org/10.1093/aob/mcl037.

Savchenko, G., Wiese, C., Neimanis, S., Hedrich, R., Heber, U., 2000. pH regulation in apoplastic and cytoplasmic cell compartments of leaves. Planta 211, 246-255. http:// dx.doi.org/10.1007/s004250000280.

Shen, Z., et al., 2009. Label-free quantitative proteomics analysis of etiolated maize seedling leaves during greening. Mol. Cell. Proteom. 8, 2443-2460. http://dx.doi. org/10.1074/mcp.M900187-MCP200.

Sule, A., Vanrobaeys, F., Hajos, G., Van Beeumen, J., Devreese, B., 2004. Proteomic 
analysis of small heat shock protein isoforms in barley shoots. Phytochemistry 65, 1853-1863. http://dx.doi.org/10.1016/j.phytochem.2004.03.030.

Szklarczyk, D., et al., 2015. STRING v10: protein-protein interaction networks, integrated over the tree of life. Nucleic Acids Res. 43, D447-D452. http://dx.doi.org/10.1093/ nar/gku1003.

Vizcaíno, J.A., Deutsch, E.W., Wang, R., Csordas, A., Reisinger, F., Ríos, D., et al., 2014. ProteomeXchange provides globally coordinated proteomics data submission and dissemination. Nat. Biotechnol. 32, 223-226. http://dx.doi.org/10.1038/nbt.2839.

Wang, J., Gan, Y.T., Clarke, F., McDonald, C.L., 2006. Response of chickpea yield to high temperature stress during reproductive development. Crop Sci. 46, 2171-2178. http://dx.doi.org/10.2135/cropsci2006.02.0092.

Wang, K., Zhang, X., Goatley, M., Ervin, E., 2014. Heat shock proteins in relation to heat stress tolerance of creeping bentgrass at different N levels. PLoS One 9, e102914. http://dx.doi.org/10.1371/journal.pone.0102914.

Wang, X., Dinler, B.S., Vignjevic, M., Jacobsen, S., Wollenweber, B., 2015. Physiological and proteome studies of responses to heat stress during grain filling in contrasting wheat cultivars. Plant Sci. 230, 33-50. http://dx.doi.org/10.1016/j.plantsci.2014.10. 009.

Weinhold, A., Wielsch, N., Svatoš, A., Baldwin, I.T., 2015. Label-free nanoUPLC-MSE based quantification of antimicrobial peptides from the leaf apoplast of Nicotiana attenuata. BMC Plant Biol. 15, 18. http://dx.doi.org/10.1186/s12870-014-0398-9.

Xu, C., Huang, B., 2008. Root proteomic responses to heat stress in two Agrostis grass species contrasting in heat tolerance. J. Exp. Bot. 59, 4183-4194. http://dx.doi.org/ $10.1093 / \mathrm{jxb} / \mathrm{ern} 258$.

Yan, S.H., Yin, Y.P., Li, W.Y., Li, Y., Liang, T.B., Wu, Y.H., Geng, Q.H., Wang, Z.L., 2008 Effect of high temperature after anthesis on starch formation of two wheat cultivars differing in heat tolerance. Acta Ecol. Sin. 28, 6138-6147. http://dx.doi.org/10. 1017/S0021859610001024.

Young, L.W., Wilen, R.W., Bonham-Smith, P.C., 2004. High temperature stress of Brassica napus during flowering reduces micro-and megagametophyte fertility, induces fruit abortion, and disrupts seed production. J. Exp. Bot. 55, 485-495. http://dx.doi.org/ 10.1093/jxb/erh038.

Zhang, Y., Xu, L., Zhu, X., Gong, Y., Xiang, F., et al., 2013. Proteomic analysis of heat stress response in leaves of radish (Raphanus sativus L.). Plant Mol. Biol. Rep. 31, 195-203. http://dx.doi.org/10.1007/s11105-012-0486-7.

Zhu, T., Provart, N.J., 2003. Transcriptional responses to low temperature and their regulation in Arabidopsis. Can. J. Bot. 81, 1168-1174. http://dx.doi.org/10.1139/ b03-115.

Zinn, K.E., Tunc-Ozdemir, M., Harper, J.F., 2010. Temperature stress and plant sexual reproduction: uncovering the weakest links. J. Exp. Bot. 61, 1959-1968. http://dx. doi.org/10.1093/jxb/erq053.

Zou, J., Liu, C., Chen, X., 2011. Proteomics of rice in response to heat stress and advances in genetic engineering for heat tolerance in rice. Plant Cell Rep. 30, 2155-2165. http://dx.doi.org/10.1007/s00299-011-1122-y. 